\title{
NH4[BAs04F] - a new layer fluoro-boroarsenate with a silicate related topology
}

\begin{tabular}{|r|l|}
\hline Journal: & Zeitschrift für Anorganische und Allgemeine Chemie \\
\hline Manuscript ID: & zaac. 200900183.R1 \\
\hline Wiley - Manuscript type: & Article \\
\hline Date Submitted by the \\
Author: & 05-Jun-2009 \\
\hline Complete List of Authors: & Weller, Mark; University of Southampton, Chemistry \\
\hline Keywords: & boroarsenate, layer structure, oxotetrahedra \\
\hline
\end{tabular}

\section{S) scholaroNE" \\ Manuscript Central}




\title{
$\mathrm{NH}_{4}\left[\mathrm{BAsO}{ }_{4} \mathrm{~F}\right]$
}

\section{a new layer fluoro-boroarsenate with a silicate related topology}

\author{
Alexandra Lieb ${ }^{a, b}$, Mark T. Weller ${ }^{a, *}$ \\ a School of Chemistry, University of Southampton, Highfield, Southampton SO17 \\ 1BJ, United Kingdom \\ b current address: Institut für Anorganische Chemie, Christian-Albrechts-Universität \\ zu Kiel, Max-Eyth-Straße 2, D-24118 Kiel, Germany
}

\begin{abstract}
The fluoro-boroarsenate $\mathrm{NH}_{4}\left[\mathrm{BAsO}_{4} \mathrm{~F}\right]$ has been obtained by the melt reaction of $\mathrm{NH}_{4} \mathrm{H}_{2} \mathrm{AsO}_{4}, \mathrm{~B}(\mathrm{OH})_{3}$ and $\mathrm{LiBF}_{4}$. The dry reaction mixture, in a $3: 3: 2$ ratio, was treated at $240{ }^{\circ} \mathrm{C}$ for 14 days. After cooling to room temperature and washing with hot water the product was isolated as colourless crystals and powder. The crystal structure was determined by single-crystal X-ray diffraction: monoclinic, space group $C c$ (no. 9), $Z=4, a=4.4307(5) \AA, b=8.0991(9) \AA, c=12.674(2) \AA, \beta=90.230(6)^{\circ}, V$ $=454.81(9) \AA^{3}, R 1=0.0456, w R 2=0.0900$, Flack parameter $=0.13(3)$. The structure consists of $\left[\mathrm{BAsO}_{4} \mathrm{~F}\right]^{-}$layers, separated by ammonium ions, having a unique orientations of the tetrahedra forming the constituent six-membered rings. The topology of the fluoro-boroarsenate layer is related to those of the silicate $\delta-\mathrm{Na}_{2} \mathrm{Si}_{2} \mathrm{O}_{5}$ and the borophosphate $\mathrm{Mg}\left(\mathrm{H}_{2} \mathrm{O}\right)_{2}\left[\mathrm{~B}_{2} \mathrm{P}_{2} \mathrm{O}_{8}(\mathrm{OH})_{2}\right] \cdot \mathrm{H}_{2} \mathrm{O}$. $\mathrm{NH}_{4}\left[\mathrm{BAsO}{ }_{4} \mathrm{~F}\right]$ was further characterised by powder X-ray diffraction, IR spectroscopy and EDX analyses.
\end{abstract}

Keywords: boroarsenate; ammonium; single crystal X-ray structure; silicate; borophosphate

\section{Introduction}


Oxotetrahedral frameworks are the most prevalent structures among framework materials, as exemplified by the large number of known zeolites, aluminophosphates and zincophosphates. The quest for structural diversity in framework materials has lead to the use of more uncommon units, e.g. borate $\mathrm{BO}_{4}$, together with other oxospecies, for example phosphate $\mathrm{PO}_{4}$, to produce a range of new structures [1]. Borate groups in a 1:1 combination with group 15 oxotetrahedra, such as $\mathrm{PO}_{4}$, produce building-blocks isoelectronic with silicates and lead to analogous structures, such as the quartz heterotype $\mathrm{BPO}_{4}$ [2], chain structures and three-dimensional frameworks $[3,4]$. This compositional equivalence also holds for the combination of borate groups with arsenate groups, where detailed investigations have only recently started [5]. Additionally, substitution of $O$ with $F$ gives rise to fluoro-boroarsenates generating further possibilities for variations of properties and structures of boroarsenate frameworks.

As $\mathrm{BPO}_{4}$ and $\mathrm{BAsO}_{4}$ are III/V-heterotype variants of quartz $\mathrm{SiO}_{2}$ [2] the potential for structural similarities among the borophosphates, boroarsenates and classical tectosilicates exists. Where $F$ substitutes, or partially substitutes, for oxygen or hydroxide in the silicates equivalent formulae to families such as the sorosilicates and inosilicates may be derived. In this paper we describe the synthesis of a new fluoro-boroarsenate, produced in a boric acid melt, with a layer structure showing a comparable but still different anionic layer to its related borophosphate and silicate structures; this demonstrates further the structural versatility of such compounds formed from linked tetrahedra. All the three structures show $6^{3}$ network layers made up from six membered tetrahedra rings but with different up/down directedness patterns of the tetrahedra.

\section{Experimental}

\subsection{Syntheses}

$\mathrm{LiBF}_{4}$ (0.469 g / 5 mmol, Sigma Aldrich, 98\%), $\mathrm{NH}_{4} \mathrm{H}_{2} \mathrm{AsO}_{4}$ (1.192 g / 7.5 mmol, $\mathrm{ABCR}, 98 \%)$ and $\mathrm{B}(\mathrm{OH})_{3}(0.460 \mathrm{~g} / 7.5 \mathrm{mmol}$, Sigma Aldrich, 99+\%) were thoroughly mixed with a pestle and mortar in a molar ratio of 2:3:3. The dry mixture was transferred into a $23 \mathrm{ml}$ Parr autoclave and treated at $240{ }^{\circ} \mathrm{C}$ for 14 days. After 
washing the resulting product mixture with hot water $\mathrm{NH}_{4}\left[\mathrm{BAsO}_{4} \mathrm{~F}\right]$ was isolated as a colourless polycrystalline powder.

\subsection{Crystal-Structure Analysis \\ 2.2.1 Single-Crystal X-Ray Analysis}

X-ray diffraction data of $\mathrm{NH}_{4}\left[\mathrm{BAsO}_{4} \mathrm{~F}\right]$ were collected on a Bruker-Nonius FR591 rotating anode diffractometer equipped with $10 \mathrm{~cm}$ confocal mirrors and a BrukerNonius APEX II CCD camera on a $\kappa$-goniostat using Mo- $\mathrm{K}_{\alpha}$ radiation. According to the observed reflection conditions of the monoclinic lattice, the space group $C c$ (no. 9) was determined. The crystal structure of $\mathrm{NH}_{4}\left[\mathrm{BAsO}_{4} \mathrm{~F}\right]$ was solved by direct methods using SHELXTL [6] and refined with anisotropic thermal displacement parameters for all atoms, except the boron atom B1 and the oxygen atom $\mathrm{O} 1$. Relevant crystallographic data and details of the X-ray data collection are shown in Table 1.

Table 1: Crystallographic data and details of the single crystal X-ray data collection for $\mathrm{NH}_{4}\left[\mathrm{BAsO}{ }_{4} \mathrm{~F}\right]$.

\begin{tabular}{|c|c|}
\hline diffractometer & Bruker-Nonius FR591 rotating anode \\
\hline monochromator & $10 \mathrm{~cm}$ confocal mirrors \\
\hline radiation & $\operatorname{Mo}_{K \alpha}(\lambda=0.71073 \AA)$ \\
\hline temperature / K & $120(2)$ \\
\hline space group & Cc (no. 9), monoclinic \\
\hline lattice parameter, a / § & $4.4307(5)$ \\
\hline$b / \AA$ & $8.0991(9)$ \\
\hline$c / \AA$ & $12.674(2)$ \\
\hline$\beta /^{\circ}$ & $90.230(6)$ \\
\hline cell volume, $V / \AA^{3}$ & $454.81(9)$ \\
\hline formula units & $Z=4$ \\
\hline crystal size / mm³ & $0.04 \times 0.04 \times 0.02$ \\
\hline crystal color & colourless \\
\hline calculated density $/ \mathrm{g} \mathrm{cm}^{-3}$ & 2.728 \\
\hline diffraction range $/{ }^{\circ}$ & $5.8<2 \theta<55$ \\
\hline measured reflections & 2092 \\
\hline independent reflections & 957 \\
\hline
\end{tabular}


observed reflections

ref. parameters / restraints

$R_{\text {int }}$

$F(000)$

absorption correction

absorption coefficient $/ \mathrm{mm}^{-1}$

min. / max. transmission

Flack parameter

min. / max. residual electron density / e / $\AA^{3}$

GooF

$R_{1}[\mathrm{I}>2 \sigma(\mathrm{I})]$

$w R_{2}[\mathrm{I}>2 \sigma(\mathrm{I})]$
914

$64 / 2$

0.0458

360.0

multi-scan, sadabs $2007 / 2$

7.414

$0.751 / 0.862$

$0.13(3)$

$-0.949 / 0.911$

1.134

$0.0456[0.0420]$

$0.0900[0.0877]$

Some selected distances and angles within the single crystal structure are shown in Table 2.

Table 2: Selected interatomic distances $(\AA)$ and angles $\left(^{\circ}\right)$ in the structure of $\mathrm{NH}_{4}\left[\mathrm{BAsO}{ }_{4} \mathrm{~F}\right]$ determined by single-crystal $\mathrm{X}$-ray diffraction with standard deviations in parentheses. Constrained values are marked with an asterisk.

\begin{tabular}{llllll}
\hline As1-O1 & $1.645(5)$ & $\mathrm{B} 1-\mathrm{O} 1$ & $1.45(1)$ & $\mathrm{N} 1-\mathrm{H} 1 \mathrm{~A}$ & $0.8391^{*}$ \\
$\mathrm{As} 1-\mathrm{O} 2$ & $1.699(5)$ & $\mathrm{B} 1-\mathrm{O} 2$ & $1.49(1)$ & $\mathrm{N} 1-\mathrm{H} 1 \mathrm{~B}$ & $0.8432^{*}$ \\
$\mathrm{As} 1-\mathrm{O} 3$ & $1.695(6)$ & $\mathrm{B} 1-\mathrm{O} 3$ & $1.47(1)$ & $\mathrm{N} 1-\mathrm{H} 1 \mathrm{C}$ & $0.8507^{*}$ \\
$\mathrm{As} 1-\mathrm{O} 4$ & $1.703(5)$ & $\mathrm{B} 1-\mathrm{F} 1$ & $1.42(1)$ & $\mathrm{N} 1-\mathrm{H} 1 \mathrm{D}$ & $0.8437^{*}$ \\
\hline $\mathrm{O} 1-\mathrm{As} 1-\mathrm{O} 2$ & $104.2(3)$ & $\mathrm{O} 1-\mathrm{B} 1-\mathrm{O} 2$ & $107.4(6)$ & $\mathrm{H} 1 \mathrm{~A}-\mathrm{N} 1-\mathrm{H} 1 \mathrm{~B}$ & $109.9^{*}$ \\
$\mathrm{O} 1-\mathrm{As} 1-\mathrm{O} 3$ & $111.1(3)$ & $\mathrm{O} 1-\mathrm{B} 1-\mathrm{O} 3$ & $115.1(6)$ & $\mathrm{H} 1 \mathrm{~A}-\mathrm{N} 1-\mathrm{H} 1 \mathrm{C}$ & $109.8^{*}$ \\
$\mathrm{O} 1-\mathrm{As} 1-\mathrm{O} 4$ & $106.0(3)$ & $\mathrm{O} 2-\mathrm{B} 1-\mathrm{O} 3$ & $107.5(7)$ & $\mathrm{H} 1 \mathrm{~B}-\mathrm{N} 1-\mathrm{H} 1 \mathrm{C}$ & $108.2^{*}$ \\
$\mathrm{O} 2-\mathrm{As} 1-\mathrm{O} 3$ & $102.8(3)$ & $\mathrm{O} 1-\mathrm{B} 1-\mathrm{F} 1$ & $111.9(7)$ & $\mathrm{H} 1 \mathrm{~A}-\mathrm{N} 1-\mathrm{H} 1 \mathrm{D}$ & $109.7^{*}$ \\
$\mathrm{O} 2-\mathrm{As} 1-\mathrm{O} 4$ & $116.3(3)$ & $\mathrm{O} 2-\mathrm{B} 1-\mathrm{F} 1$ & $109.7(6)$ & $\mathrm{H} 1 \mathrm{~B}-\mathrm{N} 1-\mathrm{H} 1 \mathrm{D}$ & 110.4 * \\
$\mathrm{O} 3-\mathrm{As} 1-\mathrm{O} 4$ & $115.9(3)$ & $\mathrm{O} 3-\mathrm{B} 1-\mathrm{F} 1$ & $105.2(6)$ & $\mathrm{H} 1 \mathrm{C}-\mathrm{N} 1-\mathrm{H} 1 \mathrm{D}$ & $108.7^{*}$ \\
\hline $\mathrm{B} 1-\mathrm{O} 1-\mathrm{As} 1$ & $128.2(5)$ & $\mathrm{B} 1-\mathrm{O} 2-\mathrm{As} 1$ & $124.4(5)$ & $\mathrm{B} 1-\mathrm{O} 3-\mathrm{As} 1$ & $124.3(5)$ \\
\hline
\end{tabular}

Details of the single crystal structures of $\mathrm{NH}_{4}\left[\mathrm{BAsO}_{4} \mathrm{~F}\right]$ may be obtained from the Fachinformationszentrum Karlsruhe, D-76344 Eggenstein-Leopoldshafen, Germany, e-mail crysdata@FIZ-karlsruhe.de, by quoting the depository number CSD-420517. 


\subsubsection{X-Ray Powder Diffraction}

An X-ray powder diffraction pattern was obtained from a sample of $\mathrm{NH}_{4}\left[\mathrm{BAsO}_{4} \mathrm{~F}\right]$ using a PANalytical X'Pert PRO MPD diffractometer in transmission geometry. The compound was measured in a flat sample holder. The detected reflections of $\mathrm{NH}_{4}\left[\mathrm{BAsO}{ }_{4} \mathrm{~F}\right]$ have been indexed and a Rietveld refinement was performed (using GSAS [7]). $\mathrm{BAsO}_{4}$ was also included as a very minor second phase contributing to the X-ray powder pattern. Some very weak additional reflections were detected deriving from an unknown by-product. The structural model of $\mathrm{NH}_{4}\left[\mathrm{BAsO}_{4} \mathrm{~F}\right]$ from single crystal was employed and the isotropic thermal displacement parameters of $B$ and $\mathrm{O}$ within $\mathrm{BAsO}_{4}$ had to be fixed to reasonable values. Relevant crystallographic data and details of the powder X-ray data collection are shown in Table 2.

Table 2: Crystallographic data and details of the powder X-ray diffraction data collection and the Rietveld refinement of $\mathrm{NH}_{4}\left[\mathrm{BAsO}_{4} \mathrm{~F}\right]$ (including $9.5 \%$ of $\mathrm{BAsO}_{4}$ )

\begin{tabular}{lc}
\hline diffractometer & PANalytical X'Pert PRO MPD \\
monochromator & none \\
detector & PSD, PIXcel (scanning mode) \\
temperature $/ \mathrm{K}$ & $293(2)$ \\
lattice parameter, $a / \AA$ & $4.43873(7)$ \\
$b / \AA$ & $8.0986(2)$ \\
$c / \AA$ & $12.7502(3)$ \\
$\beta / \circ$ & $90.242(2)$ \\
cell volume, $V / \AA^{3}$ & $458.34(2)$ \\
observed reflections (total) & 340 \\
ref. Parameters & 59 \\
GooF $($ all data) & 3.67 \\
$R_{\mathrm{wp}} / R_{p}$ & $0.1302 / 0.0788$ \\
$R_{\mathrm{F}}{ }^{2}$ of $\mathrm{NH}_{4}\left[\mathrm{BAsO}{ }_{4} \mathrm{~F}\right] / \mathrm{BAsO}_{4}$ & $0.0295 / 0.0594$ \\
red. $\chi^{2}$ & 13.14 \\
\hline
\end{tabular}

\subsection{Vibrational spectroscopy}

Mid-IR spectra were recorded on an ATI Matheson Genesis in the spectral range $4000-400 \mathrm{~cm}^{-1}$. The sample was thoroughly ground together with dried $\operatorname{KBr}(\sim 1 \mathrm{mg}$ sample / $150 \mathrm{mg} \mathrm{KBr}$ ) and a pellet was prepared for the measurement. 


\subsection{EDX analysis}

Qualitative chemical analyses on the microscale by energy dispersive X-ray spectroscopy (EDX) were carried out with a Jeol JSM-5910 scanning electron microscope equipped with an energy dispersive X-ray (EDX) analyzer using an accelerating voltage of $15 \mathrm{kV}$ and INCA software.

\section{Results and Discussion}

\subsection{Crystal Structure}

The structure of $\mathrm{NH}_{4}\left[\mathrm{BAsO}_{4} \mathrm{~F}\right]$ represents a new layer structure type in the family of boroarsenate compounds. It consists of anionic tetrahedra layers and $\mathrm{NH}_{4}{ }^{+}$cations (Figure 1).
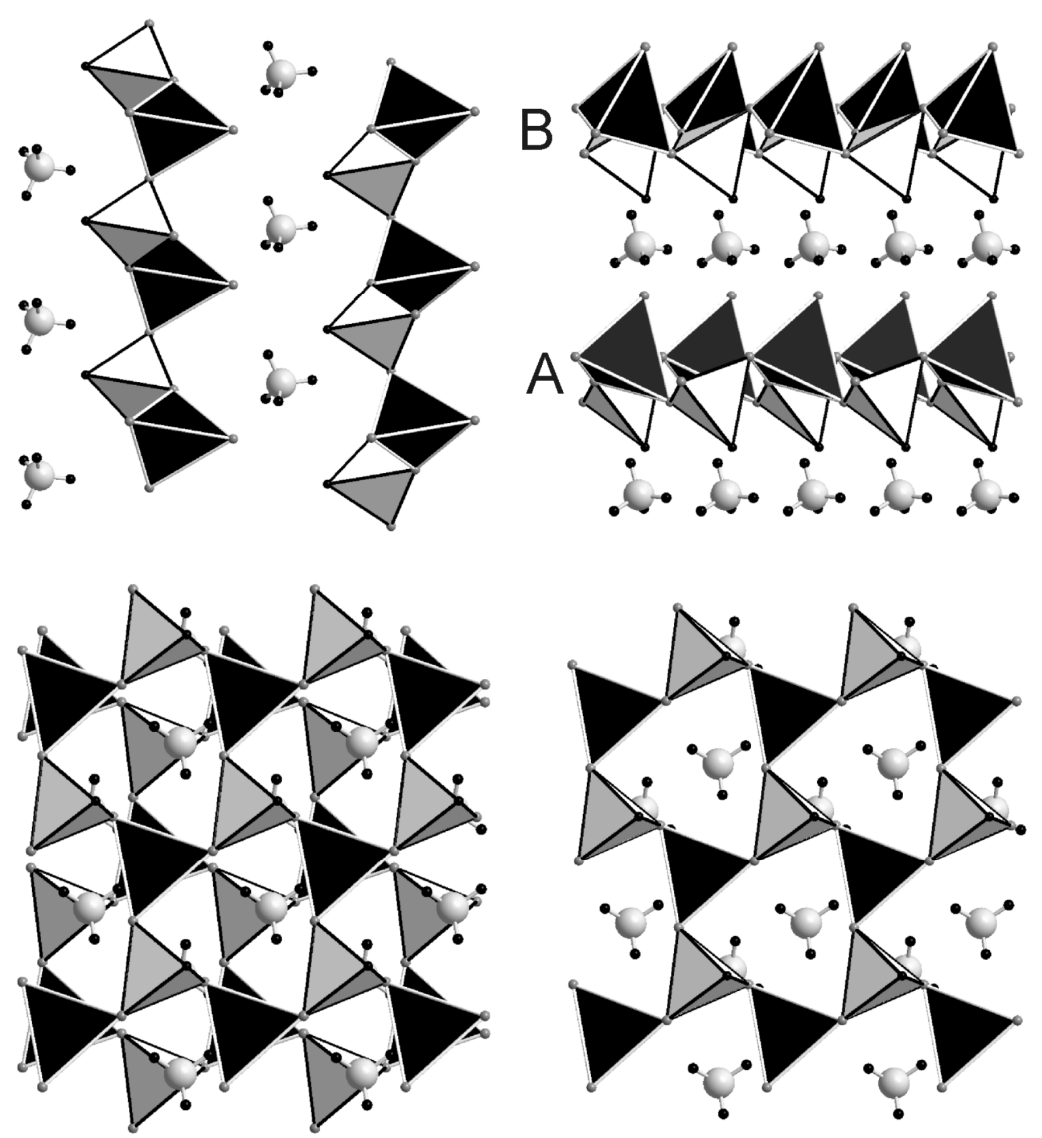

Figure 1: Structural overview of $\mathrm{NH}_{4}\left[\mathrm{BAsO}_{4} \mathrm{~F}\right]$, view along a (top left), view along $b$ (top right) showing the stacking of the layers in an ABAB manner, view along $c$ (bottom left) of two layers of the structure demonstrating the staggered arrangement 
and (bottom right) view of only one layer displaying the $6^{3}$ network structure. Light grey tetrahedra: $\mathrm{BO}_{3} \mathrm{~F}$, black spheres: fluorine atoms, black tetrahedra: $\mathrm{AsO}_{4}$, grey spheres: oxygen atoms, large light grey spheres: nitrogen atoms, small black spheres: hydrogen atoms.

The anionic layers $\left[\mathrm{BAsO}_{4} \mathrm{~F}\right]^{-}$are topologically related to the $\left[\mathrm{Si}_{2} \mathrm{O}_{5}\right]^{2-}$ layers of the silicate $\delta-\mathrm{Na}_{2} \mathrm{Si}_{2} \mathrm{O}_{5}$ [8] and the $\left[\mathrm{BPO}_{4}(\mathrm{OH})\right]^{-}$layers of the borophosphate $\mathrm{Mg}\left(\mathrm{H}_{2} \mathrm{O}\right)_{2}\left[\mathrm{~B}_{2} \mathrm{P}_{2} \mathrm{O}_{8}(\mathrm{OH})_{2}\right] \cdot \mathrm{H}_{2} \mathrm{O}[9]$.

The fluoro-boroarsenate layers consist solely of $Q^{3}$ tetrahedra, which is typical for unbranched single layer structures. The terminal ligand atoms are oxygen atoms from $\mathrm{AsO}_{4}$ tetrahedra and fluorine atoms from $\mathrm{BO}_{3} \mathrm{~F}$ tetrahedra. The basic building unit $(\mathrm{BBU})$ of the layer is a fluoro-boroarsenate dimer $\left[\mathrm{BAsO}_{6} \mathrm{~F}\right]$ and three of these form the fundamental building unit (FBU) of the structure, which is a six membered tetrahedra ring $\left[\mathrm{B}_{3} \mathrm{As}_{3} \mathrm{O}_{15} \mathrm{~F}_{3}\right]$. These six membered rings form $6^{3}$ networks which can be found quite frequently in silicate layer structures. Following Burns [10] the building units of $\mathrm{NH}_{4}\left[\mathrm{BAsO}_{4} \mathrm{~F}\right]$ are characterised with the symbols $2 \square: 2 \square$ (dimeric unit) and $6 \square:<6 \square>$ (six membered ring). According to Liebau [11] the layer is classified as an unbranched zweier single layer, also referring to a tetrahedra dimer as the repeating unit of the structure (Figure 2).
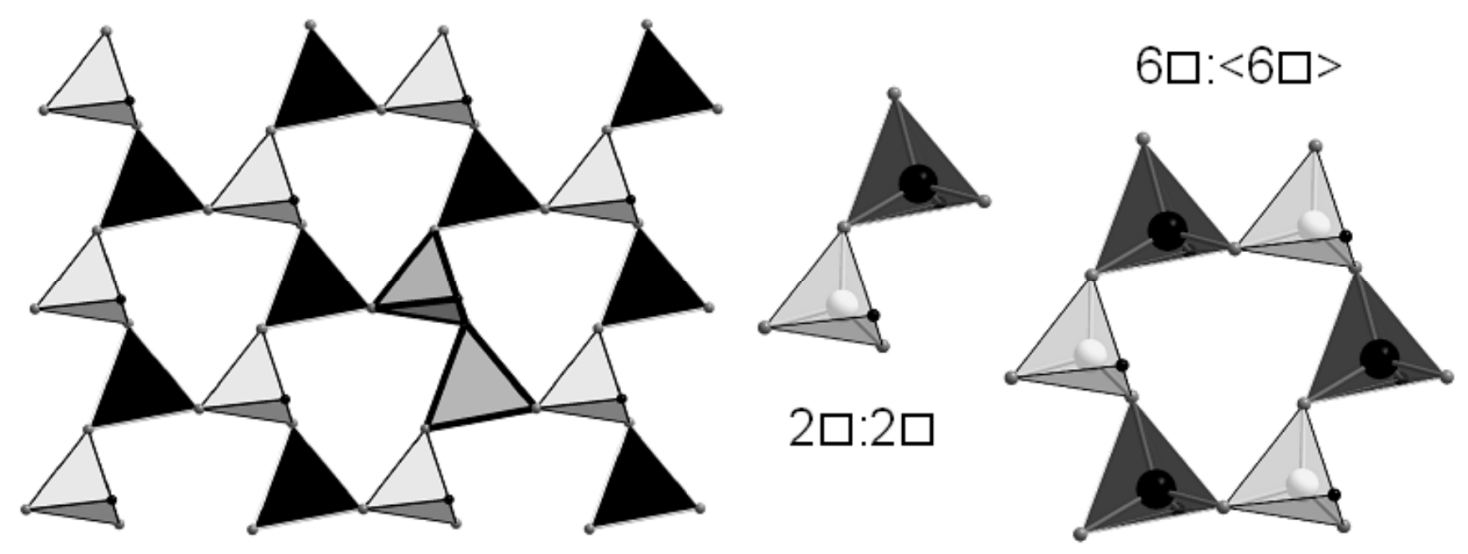

Figure 2: Classification of the anionic layer in $\mathrm{NH}_{4}\left[\mathrm{BAsO}_{4} \mathrm{~F}\right]$ (view along c). On the left side the classification according to Liebau is displayed, the layer is called an unbranched zweier single layer, the repeating unit is emphasised as grey tetrahedra with thick black edges. On the right side the basic building unit (BBU), a fluoroboroarsenate dimer and the fundamental building unit (FBU) a six membered ring are 
shown. The symbols follow the nomenclature suggested by Burns. White tetrahedra: $\mathrm{BO}_{3} \mathrm{~F}$, black tetrahedra: $\mathrm{AsO}_{4}$, small grey spheres: oxygen atoms, small black spheres: fluorine atoms, large white spheres: boron atoms, large black spheres: arsenic atoms.

Comparing $\mathrm{NH}_{4}\left[\mathrm{BAsO}_{4} \mathrm{~F}\right]$ with the structures of the silicate $\delta-\mathrm{Na}_{2} \mathrm{Si}_{2} \mathrm{O}_{5}$ and the borophosphate $\mathrm{Mg}\left(\mathrm{H}_{2} \mathrm{O}\right)_{2}\left[\mathrm{~B}_{2} \mathrm{P}_{2} \mathrm{O}_{8}(\mathrm{OH})_{2}\right] \cdot \mathrm{H}_{2} \mathrm{O}$, which contains layer of the same connectivity i.e. $\left[\mathrm{Si}_{2} \mathrm{O}_{5}\right]^{2-}$ and $\left[\mathrm{BPO}_{4}(\mathrm{OH})\right]^{-}$also forming $6^{3}$ networks, some important differences can be observed. Most importantly the corrugation of the three layers is different, increasing from $\mathrm{NH}_{4}\left[\mathrm{BAsO}{ }_{4} \mathrm{~F}\right]$ via $\delta-\mathrm{Na}_{2} \mathrm{Si}_{2} \mathrm{O}_{5}$ to $\mathrm{Mg}\left(\mathrm{H}_{2} \mathrm{O}\right)_{2}\left[\mathrm{~B}_{2} \mathrm{P}_{2} \mathrm{O}_{8}(\mathrm{OH})_{2}\right] \cdot \mathrm{H}_{2} \mathrm{O}$ (Figure 3), which shows a tuning of the layer element of these structures in response to the different cations contained within them, i.e. $\mathrm{NH}_{4}{ }^{+}$, $\mathrm{Na}^{+}, \mathrm{Mg}^{2+}$.

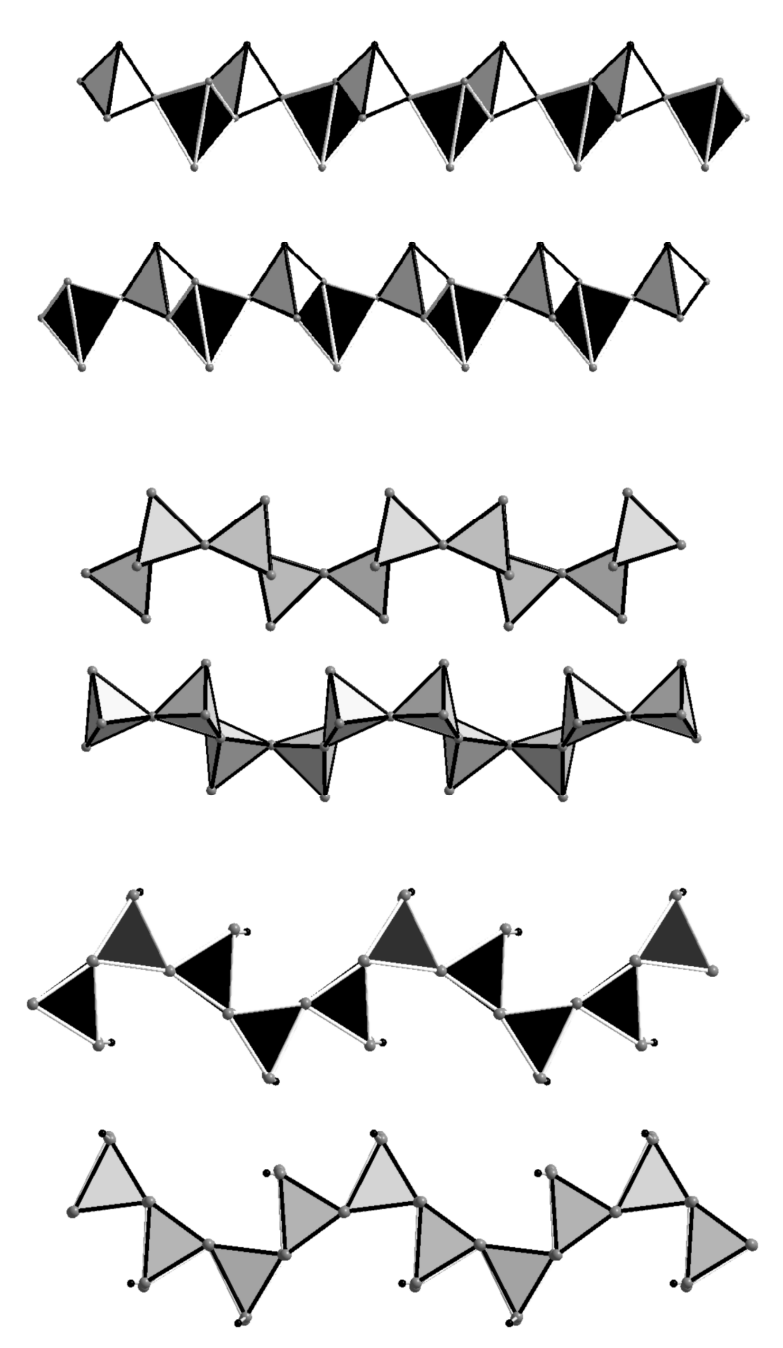


Figure 3: Comparison of the different corrugation of the layers of $\mathrm{NH}_{4}\left[\mathrm{BAsO}_{4} \mathrm{~F}\right]$ (top, light grey tetrahedra: $\mathrm{BO}_{3} \mathrm{~F}$, black tetrahedra: $\mathrm{AsO}_{4}$ ), $\delta-\mathrm{Na}_{2} \mathrm{Si}_{2} \mathrm{O}_{5}$ (middle, medium grey tetrahedra: $\mathrm{SiO}_{4}$ ) and $\mathrm{Mg}\left(\mathrm{H}_{2} \mathrm{O}\right)_{2}\left[\mathrm{~B}_{2} \mathrm{P}_{2} \mathrm{O}_{8}(\mathrm{OH})_{2}\right] \cdot \mathrm{H}_{2} \mathrm{O}$ (bottom, light grey tetrahedra: $\mathrm{BO}_{4} \mathrm{H}$, black tetrahedra: $\mathrm{PO}_{4}$ ).

Also the directedness of the tetrahedra, meaning the orientation of the tetrahedra, pointing either up $(\mathrm{U})$ or down $(\mathrm{D})$, within the layers is different in each of these structures. This can be easily realised by considering the patterns of the six membered rings which is UDUDUD for $\mathrm{NH}_{4}\left[\mathrm{BAsO}_{4} \mathrm{~F}\right]$, UUDUUD or DDUDDU for adjacent layers in $\delta-\mathrm{Na}_{2} \mathrm{Si}_{2} \mathrm{O}_{5}$ and UUDDDD or DDUUUU in neighbouring layers $\mathrm{Mg}\left(\mathrm{H}_{2} \mathrm{O}\right)_{2}\left[\mathrm{~B}_{2} \mathrm{P}_{2} \mathrm{O}_{8}(\mathrm{OH})_{2}\right] \cdot \mathrm{H}_{2} \mathrm{O}$ (Figure 4).
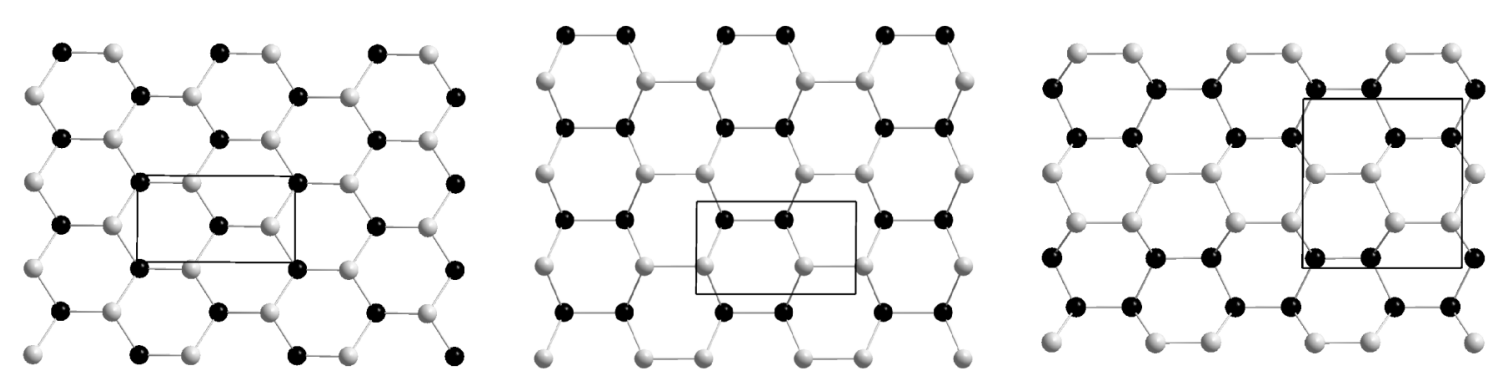

Figure 4: Comparison of the directedness patterns of the layers of $\mathrm{NH}_{4}\left[\mathrm{BAsO}_{4} \mathrm{~F}\right]$ (left), $\delta-\mathrm{Na}_{2} \mathrm{Si}_{2} \mathrm{O}_{5}$ (middle) and $\mathrm{Mg}\left(\mathrm{H}_{2} \mathrm{O}\right)_{2}\left[\mathrm{~B}_{2} \mathrm{P}_{2} \mathrm{O}_{8}(\mathrm{OH})_{2}\right] \cdot \mathrm{H}_{2} \mathrm{O}$ (right). White spheres symbolise tetrahedra pointing up $(\mathrm{U})$, black spheres symbolise tetrahedra pointing down (D). The grey lines symbolise the topological connection of the tetrahedra and visualise the $6^{3}$ networks of the structures.

The $\mathrm{NH}_{4}^{+}$cations in $\mathrm{NH}_{4}\left[\mathrm{BAsO}_{4} \mathrm{~F}\right]$ are located in a strongly distorted (4+2) six-fold co-ordination sphere forming three strong single and one trifurcated hydrogen bonds to terminal oxygen and fluorine atoms of the layers (Figure 5, Table 4). This hydrogen-bonded arrangement helps explain the relative orientation of adjacent $\left[\mathrm{BAsO}_{4} \mathrm{~F}\right]^{-}$layers giving rise to the non-centrosymmetric space group $\mathrm{C} c$. 


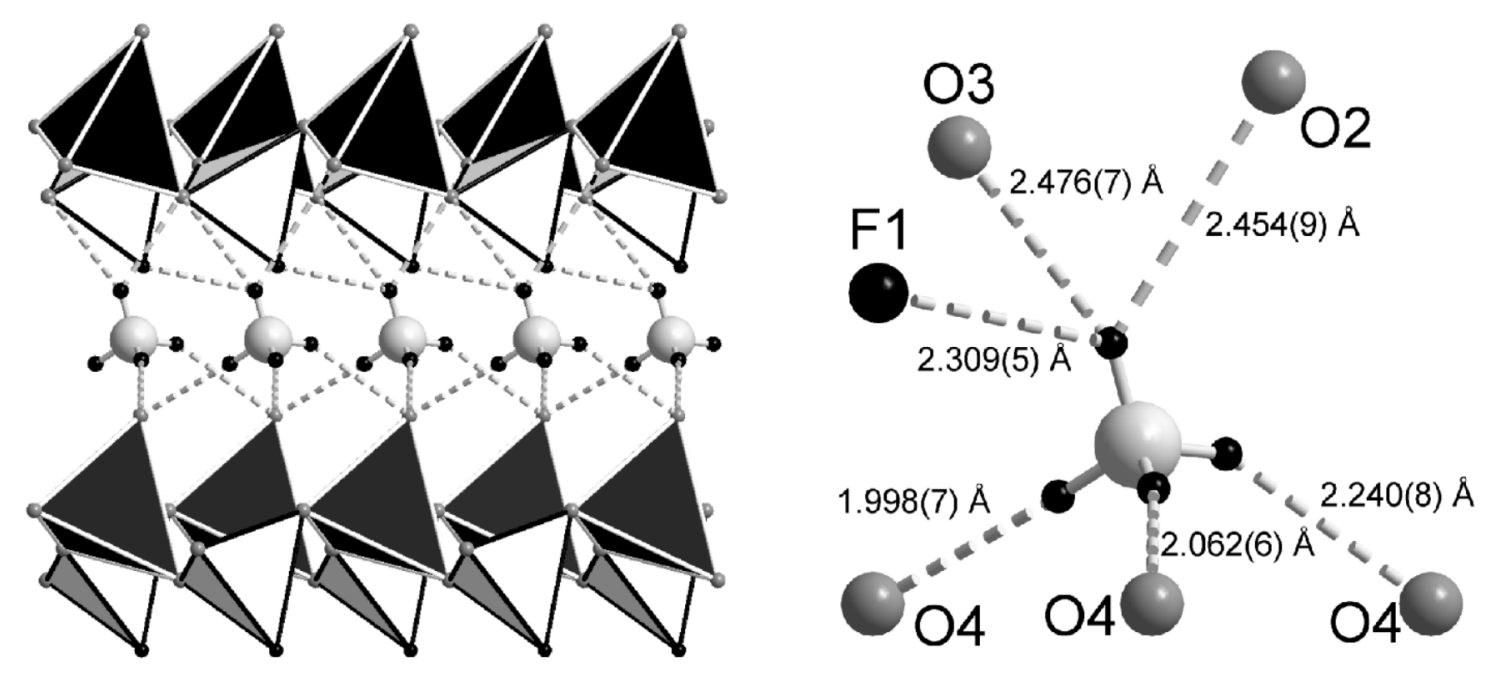

Figure 5: Surrounding of the $\mathrm{NH}_{4}{ }^{+}$cations in $\mathrm{NH}_{4}\left[\mathrm{BAsO}_{4} \mathrm{~F}\right]$ showing the interactions of the hydrogen atom with the nearest oxygen and fluorine atoms (right side). On the left side the $\mathrm{NH}_{4}{ }^{+}$cations are shown between the fluoro-boroarsenate layers, hydrogen bonds are displayed as dashed lines (view along b). Large light grey spheres: nitrogen atoms, small black spheres: hydrogen atoms, medium size black spheres: fluorine atoms, medium size grey spheres: oxygen atoms.

Table 4: Hydrogen bonds of the $\mathrm{NH}_{4}{ }^{+}$cations to the fluoro-boroarsenate layers in $\mathrm{NH}_{4}\left[\mathrm{BAsO}_{4} \mathrm{~F}\right]$

\begin{tabular}{|c|c|c|c|c|}
\hline donor-H-acceptor & $d(D-H) / \AA$ & $d(H \ldots A) / \AA$ & angle $\mathrm{DHA} /{ }^{\circ}$ & $d(D \ldots A) / \AA$ \\
\hline $\begin{array}{l}\mathrm{N} 1-\mathrm{H} 1 \mathrm{~A} \ldots \mathrm{O} 4 \\
{[\mathrm{x}+1 / 2, \mathrm{y}-1 / 2, \mathrm{z}]}\end{array}$ & $0.839(6)$ & $2.062(6)$ & $170.9(5)$ & $2.894(9)$ \\
\hline $\begin{array}{l}\mathrm{N} 1-\mathrm{H} 1 \mathrm{~B} \ldots \mathrm{O} 4 \\
{[\mathrm{x}+1, \mathrm{y}-1, \mathrm{z}]}\end{array}$ & $0.843(6)$ & $2.240(8)$ & $152.8(5)$ & $3.02(1)$ \\
\hline $\begin{array}{l}\mathrm{N} 1-\mathrm{H} 1 \mathrm{C} \ldots \mathrm{O} 4 \\
{[\mathrm{x}, \mathrm{y}-1, \mathrm{z}]}\end{array}$ & $0.851(7)$ & $1.998(7)$ & $175.8(5)$ & $2.85(1)$ \\
\hline $\begin{array}{l}\text { N1-H1D...F1 } \\
{[x-1 / 2,-y+1 / 2, z-1 / 2]}\end{array}$ & $0.844(6)$ & $2.309(5)$ & $115.5(5)$ & $2.78(1)$ \\
\hline $\begin{array}{l}\mathrm{N} 1-\mathrm{H} 1 \mathrm{D} \ldots \mathrm{O} 2 \\
{[\mathrm{x},-\mathrm{y}+1, \mathrm{z}-1 / 2]}\end{array}$ & $0.844(6)$ & $2.454(9)$ & $133.5(5)$ & $3.10(2)$ \\
\hline $\begin{array}{l}\text { N1-H1D...O3 } \\
{[x,-y, z-1 / 2]}\end{array}$ & $0.844(6)$ & $2.476(7)$ & $131.5(5)$ & $3.10(1)$ \\
\hline
\end{tabular}

Additionally a Rietveld refinement of the X-ray powder data of $\mathrm{NH}_{4}\left[\mathrm{BAsO}_{4} \mathrm{~F}\right]$ was performed to confirm the structure model and the final profile fit plot obtained is shown in Figure 6. $\mathrm{BAsO}_{4}$ was refined as an additional phase and the phase fraction was found to be $9.5 \%$. The hydrogen positions of the structure model of $\mathrm{NH}_{4}\left[\mathrm{BAsO}{ }_{4} \mathrm{~F}\right]$ were included in the structure model but not refined. 


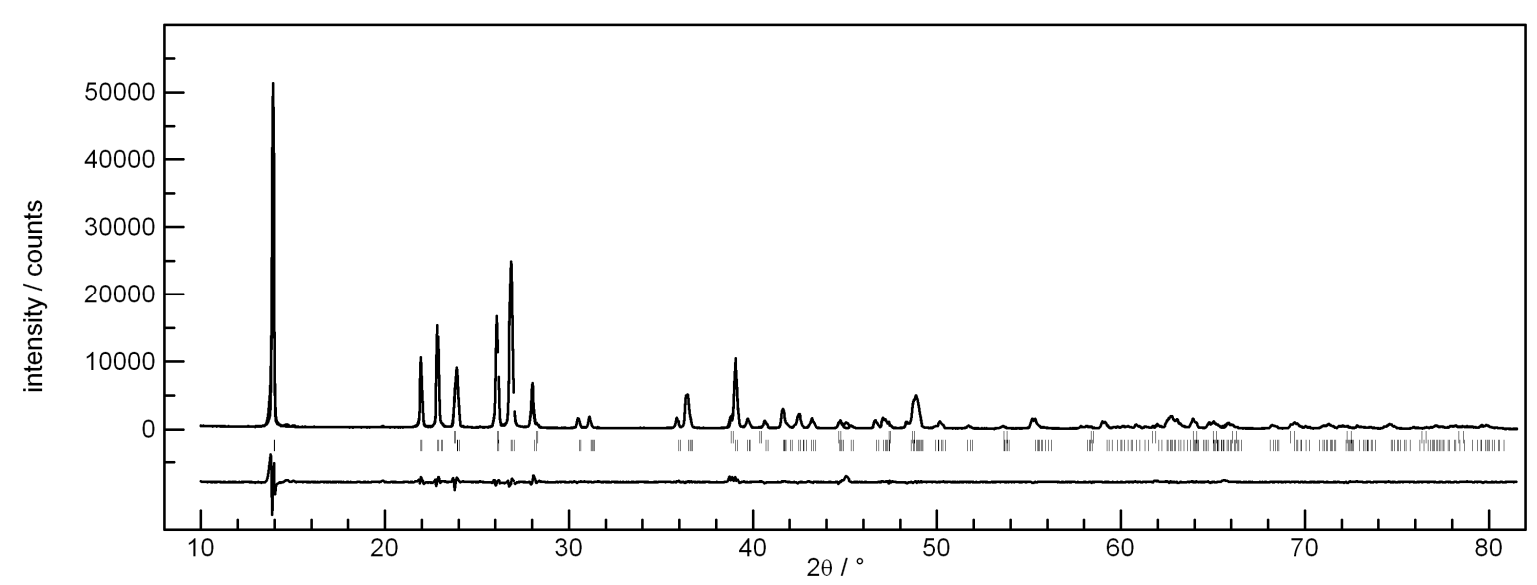

Figure 6: Rietveld profile fit of the powder X-ray data at ambient temperature of $\mathrm{NH}_{4}\left[\mathrm{BAsO}_{4} \mathrm{~F}\right]$. Observed (crosses) and calculated (line) powder diffractograms as well as difference profile (lower line). The two rows of vertical lines indicate the possible reflection positions of the refined phases, the upper row shows $\mathrm{BAsO}_{4}$, the lower row shows $\mathrm{NH}_{4}\left[\mathrm{BAsO}_{4} \mathrm{~F}\right]$. The small peaks in the difference curve around $14.5^{\circ}$ and $45^{\circ} 2$ theta indicate the presence of an additional unknown phase.

\subsection{Further characterisation of $\mathrm{NH}_{4}\left[B A s O_{4} F\right]$ by spectroscopy and $E D X$}

The presence of ammonium ions and its hydrogen bonding could be confirmed by IR spectroscopy (Figure 7). 


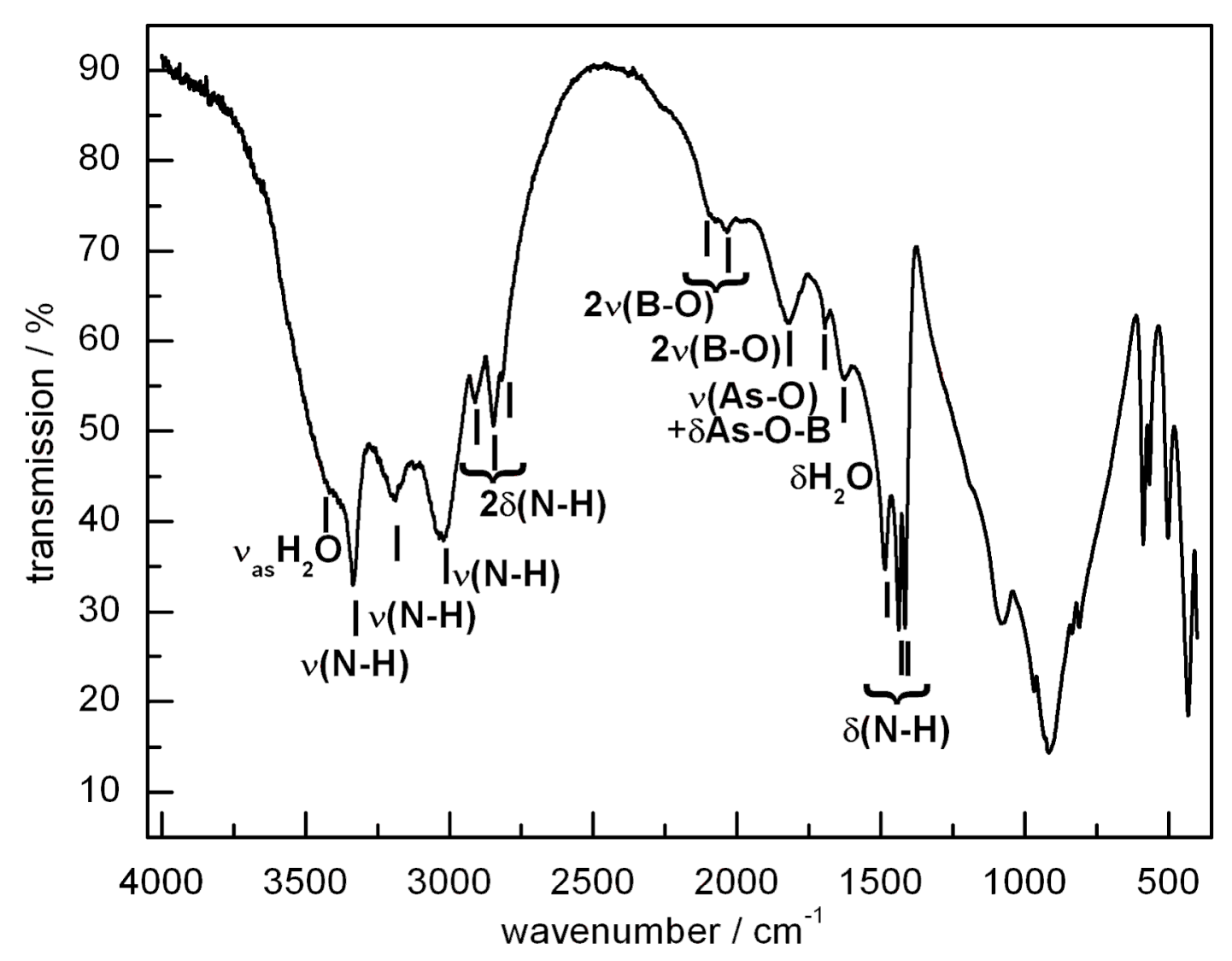

Figure 7: Mid-IR spectrum of $\mathrm{NH}_{4}\left[\mathrm{BAsO}_{4} \mathrm{~F}\right]$.

The bands could be assigned as following: $v\left(\mathrm{H}_{2} \mathrm{O}\right)$ as broad band around $3420 \mathrm{~cm}^{-1}, v(\mathrm{~N}-\mathrm{H}): 3334 \mathrm{~cm}^{-1}, 3195 \mathrm{~cm}^{-1}, 3024 \mathrm{~cm}^{-1}, 2 \delta(\mathrm{N}-\mathrm{H}): 2910 \mathrm{~cm}^{-1}, 2847 \mathrm{~cm}^{-1}$, $2817 \mathrm{~cm}^{-1}, 2 \delta(\mathrm{B}-\mathrm{O}): 2090 \mathrm{~cm}^{-1}, 2037 \mathrm{~cm}^{-1}, 2 v(\mathrm{~B}-\mathrm{O}): 1822 \mathrm{~cm}^{-1}, v($ As-O $)+\delta($ As-O-B): $1695 \mathrm{~cm}^{-1}, \delta\left(\mathrm{H}_{2} \mathrm{O}\right): 1630 \mathrm{~cm}^{-1}, \delta(\mathrm{N}-\mathrm{H}): 1486 \mathrm{~cm}^{-1}, 1438 \mathrm{~cm}^{-1}, 1416 \mathrm{~cm}^{-1}$. The lower bands derive from different combinations of framework vibrations.

Using EDX, a powder sample of $\mathrm{NH}_{4}\left[\mathrm{BAsO}_{4} \mathrm{~F}\right]$ was investigated. The measurement shows the presence of fluorine, oxygen, nitrogen and arsenic in the sample. Due to the low atom number of fluorine, oxygen and nitrogen a quantification was not possible. Boron could not be detected because its low atomic weight which is below the detectable value of the apparatus.

\section{Conclusions}


A new member of the boroarsenate family, the fluoro-boroarsenate $\mathrm{NH}_{4}\left[\mathrm{BAsO}_{4} \mathrm{~F}\right]$, has been synthesised and characterised. This material is formed under "dry" synthesis conditions with boric acid as the reaction medium but also a reactant. The investigation of its structure and the relationship to the structures of the silicate $\delta-\mathrm{Na}_{2} \mathrm{Si}_{2} \mathrm{O}_{5}$ and the borophosphate $\mathrm{Mg}\left(\mathrm{H}_{2} \mathrm{O}\right)_{2}\left[\mathrm{~B}_{2} \mathrm{P}_{2} \mathrm{O}_{8}(\mathrm{OH})_{2}\right] \cdot \mathrm{H}_{2} \mathrm{O}$ shows the interesting differences of these tetrahedra framework compounds related by substitution of the tetrahedra centre atoms.

\section{Acknowledgements}

The authors would like to thank the Deutsche Forschungsgemeinschaft (DFG grant Li 1668/1-1) for financial support.

\section{References}

${ }^{1}$ B. Ewald, Y.-X. Huang, R. Kniep, Z. Anorg. Allg. Chem. 2007, 633, 1517.

${ }^{2}$ G.E.R. Schulze, Z. Phys. Chem. 1934, 24, 215.

${ }^{3}$ R. Kniep, G. Gözel, B. Eisenmann, C. Röhr, M. Asbrand, M. Kizilyalli, Angew. Chem. Int. Ed. Engl. 1994, 34, 749.

${ }^{4}$ R. Kniep, H. Engelhardt, C. Hauf, Chem. Mater. 1998, 10, 2930.

${ }^{5}$ S. B. Wiggin, M. T. Weller, J. Am Chem. Soc. 2005, 127, 17172.

${ }^{6}$ G.M. Sheldrick, SHELXS97, Program for the Solution of Crystal Structures and SHELXL97, Program for the Refinement of Crystal Structures, University of Göttingen (1997).

7 R.B. Von Dreele, A.C. Larson, Programm GSAS General Structure Analysis System, Los Alamos National Laboratory, Los Alamos, 2001.

${ }^{8}$ V. Kahlenberg, G. Dörsam, M. Wendschuh-Josties, R. X. Fischer, J. Solid State Chem. 1999, 146, 380.

${ }^{9}$ B. Ewald, Y. Öztan, Y. Prots, R. Kniep, Z. Anorg. Allg. Chem. 2005, 631, 1615.

${ }^{10}$ P.C. Burns, J. D. Grice, F. C. Hawthorne, Canad. Mineral. 1995, 33, 1131.

${ }^{11}$ F. Liebau, Structural Chemistry of Silicates, Springer-Verlag, Berlin Heidelberg 1985. 

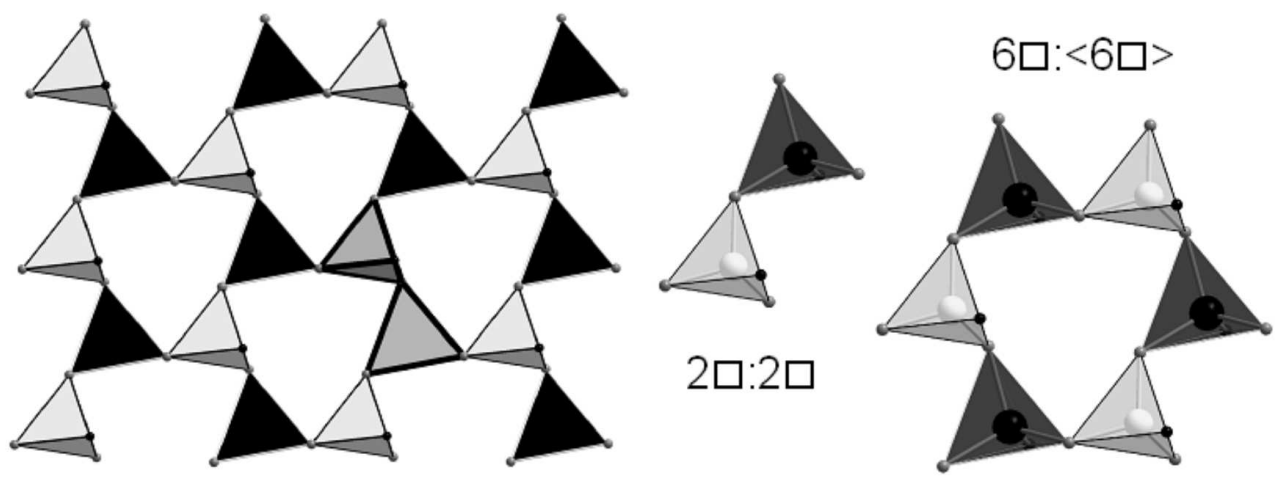

Figure 2: Classification of the anionic layer in $\mathrm{NH} 4[\mathrm{BAsO} 4 \mathrm{~F}]$ (view along c). On the left side the classification according to Liebau is displayed, the layer is called an unbranched zweier single layer, the repeating unit is emphasised as grey tetrahedra with thick black edges. On the right side the basic building unit (BBU), a fluoro-boroarsenate dimer and the fundamental building unit (FBU) a six membered ring are shown. The symbols follow the nomenclature suggested by Burns. White tetrahedra: BO3F, black tetrahedra: AsO4, small grey spheres: oxygen atoms, small black spheres: fluorine atoms, large white spheres: boron atoms, large black spheres: arsenic atoms. 
Figure 3: Comparison of the different corrugation of the layers of $\mathrm{NH4[BAsO4F]} \mathrm{(top,} \mathrm{light} \mathrm{grey}$ tetrahedra: $\mathrm{BO} 3 \mathrm{~F}$, black tetrahedra: $\mathrm{AsO} 4), \delta \mathrm{Na} 2 \mathrm{Si} 2 \mathrm{O} 5$ (middle, medium grey tetrahedra: $\mathrm{SiO} 4)$ and $\mathrm{Mg}(\mathrm{H} 2 \mathrm{O}) 2[\mathrm{~B} 2 \mathrm{P} 2 \mathrm{O} 8(\mathrm{OH}) 2] \bullet \mathrm{H} 2 \mathrm{O}$ (bottom, light grey tetrahedra: $\mathrm{BO} 4 \mathrm{H}$, black tetrahedra:PO4). 

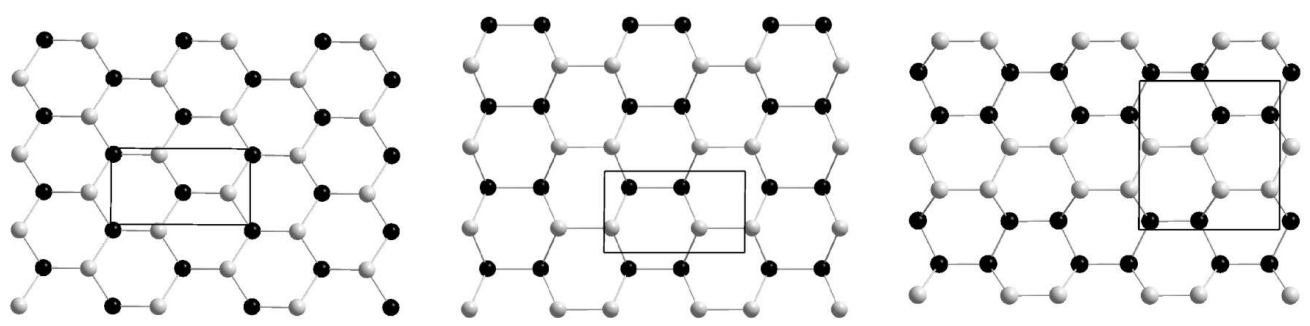

Figure 4: Comparison of the directedness patterns of the layers of NH4[BAsO4F] (left), $\delta \mathrm{Na} 2 \mathrm{Si} 2 \mathrm{O} 5$ (middle) and $\mathrm{Mg}(\mathrm{H} 2 \mathrm{O}) 2[\mathrm{~B} 2 \mathrm{P} 2 \mathrm{O} 8(\mathrm{OH}) 2] \bullet \mathrm{H} 2 \mathrm{O}$ (right). White spheres symbolise tetrahedra pointing up (U), black spheres symbolise tetrahedra pointing down (D). The grey lines symbolise the topological connection of the tetrahedra and visualise the 63 networks of the structures. 

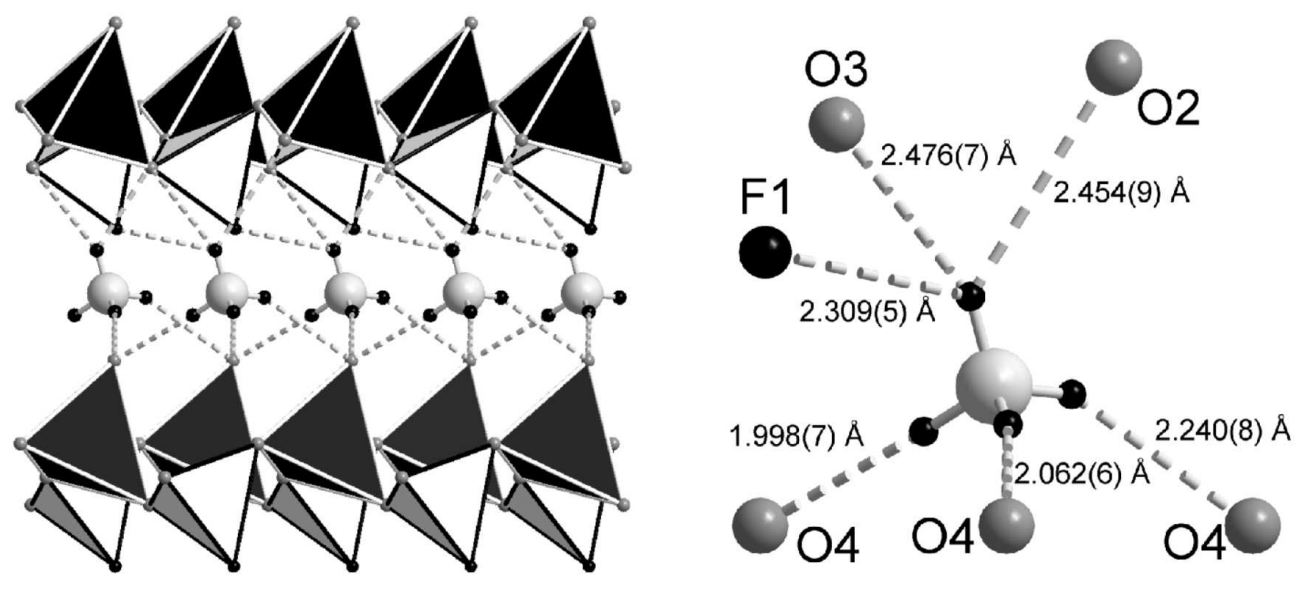

Figure 5: Surrounding of the $\mathrm{NH} 4+$ cations in $\mathrm{NH} 4[\mathrm{BAsO} 4 \mathrm{~F}]$ showing the interactions of the hydrogen atom with the nearest oxygen and fluorine atoms (right side). On the left side the $\mathrm{NH} 4+$ cations are shown between the fluoro-boroarsenate layers, hydrogen bonds are displayed as dashed lines (view along b). Large light grey spheres: nitrogen atoms, small black spheres: hydrogen atoms, medium size black spheres: fluorine atoms, medium size grey spheres: oxygen atoms. 
Figure 6: Rietveld profile fit of the powder X-ray data at ambient temperature of NH4[BAsO4F]. Observed (crosses) and calculated (line) powder diffractograms as well as difference profile (lower line). The two rows of vertical lines indicate the possible reflection positions of the refined phases, the upper row shows BAsO4, the lower row shows NH4[BAsO4F]. The small peaks in the difference curve around $14.5^{\circ}$ and $45^{\circ} 2$ theta indicate the presence of an additional unknown phase. 


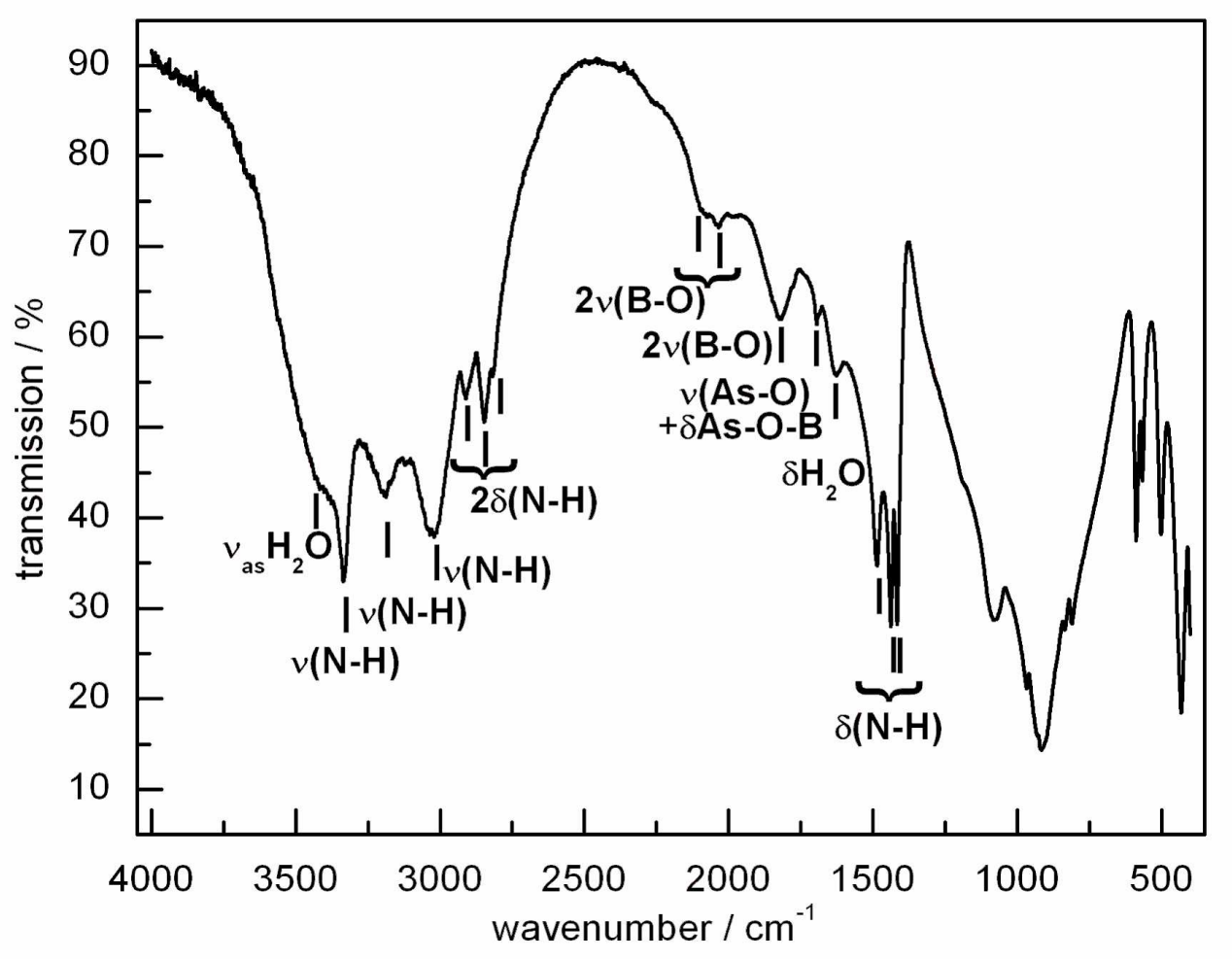

Figure 7: Mid-IR spectrum of NH4[BAsO4F]. 

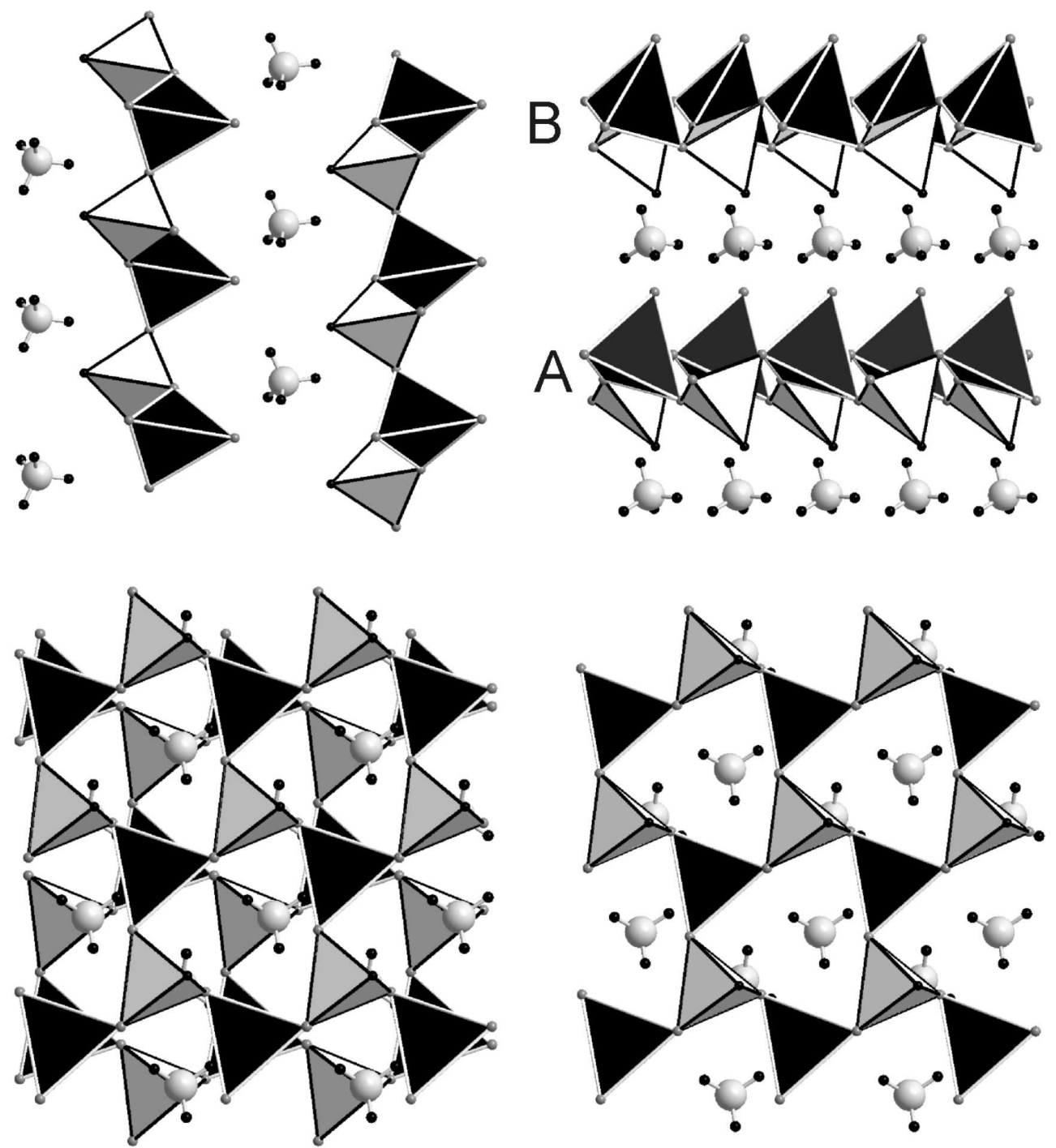

Figure 1: Structural overview of $\mathrm{NH} 4[\mathrm{BAsO} 4 \mathrm{~F}]$, view along a (top left), view along b (top right) showing the stacking of the layers in an ABAB manner, view along c (bottom left) of two layers of the structure demonstrating the staggered arrangement and (bottom right) view of only one layer displaying the 63 network structure. Light grey tetrahedra: BO3F, black spheres: fluorine atoms, black tetrahedra: AsO4, grey spheres: oxygen atoms, large light grey spheres: nitrogen atoms, small black spheres: hydrogen atoms. 